\title{
The Impact of Teachers' Behaviour on Students' Psychological and Social Development in Pakistan
}

\author{
Shazia Kausar ${ }^{*}$, Rida Shoukat, Iqra Zafar \\ Department of Education, Government College Women University, 38000, Faisalabad, Punjab, Pakistan
}

Received July 23, 2020; Revised October 20, 2020; Accepted November 1, 2020

\section{Cite This Paper in the following Citation Styles}

(a): [1] Shazia Kausar, Rida Shoukat, Iqra Zafar , "The Impact of Teachers' Behaviour on Students' Psychological and Social Development in Pakistan," Universal Journal of Educational Research, Vol. 8, No. 12, pp. 6925 - 6931, 2020. DOI: 10.13189/ujer.2020.081259.

(b): Shazia Kausar, Rida Shoukat, Iqra Zafar (2020). The Impact of Teachers' Behaviour on Students' Psychological and Social Development in Pakistan. Universal Journal of Educational Research, 8(12), 6925 - 6931. DOI: 10.13189/ujer.2020.081259.

Copyright $\odot 2020$ by authors, all rights reserved. Authors agree that this article remains permanently open access under the terms of the Creative Commons Attribution License 4.0 International License

\begin{abstract}
This paper focused on finding out the impact of teachers' behaviour on students' psychological and social development in Pakistan. Better psychological and social health is a crucial point for any student to gain better academic achievements. The teachers are the most vital position in students' lives and their classrooms. Teachers have the responsibility to educate the children that are placed in their trust. All through the rest of their lives, children carry what they are taught at a young age. They will use that which they have learned to influence society. The sample consisted of a hundred and thirty high school students to complete questionnaires, with two schools' teachers from each school as observations. The objective of this study is to examine and explore those factors that can affect the students' psychological and social development from the teacher's behaviour. The research shows that if teachers treat students unfairly, they will lose their trust and leadership for teachers and have less confidence due to their home environment and less teacher-student interaction. Teachers were polite, open, professional and well-prepared to cooperate. There was a significantly secure connection between the conduct of teachers and the educational outcomes ratings of students. Critical suggestions from the research were skilled and experienced teachers, student's encouragement, undue favouritism, etc.
\end{abstract}

Keywords Personality, Teacher's Behaviour, Psychological, Social Development, Confidence, Teacher Student Interactions

\section{Introduction}

Behaviour is a summary of the measurable effects of learners and instructor success in various educational practices. Behaviour can be either positive or negative and may be useful or unproductive. Dynamic behaviour yields the most necessary outcomes. At a different time, the behaviour is an action. There are three kinds of behaviour, think, feel and do. Cognitive, affective, and psychomotor behaviour is also generally known. Cognitive functioning involves students in thinking, remembering, evaluating, and problem-solving processes. Emotional response respects the emotions and practices of the learner. Those are psychomotor habits, learner participation, sort of physical operation. The way the teacher is allocating time to spend on teaching practices has an impact on student's achievement. Proper management of the classroom can lead to better accomplishment of the students. It includes active development, setting rules which are sensible and not unnecessary in quantity, and organizing the class to go efficiently with the instruction. Skills needed to maintain a hands-on classroom, including group notifying, witnessing, conflicting, using the least intervention principle and smooth transition.

It is anticipated that a successful teacher would be dedicated to his job and have the capacity to take responsibility. It is required to devote an excellent teacher to its work, and then have the courage to assume duty. Being professional, teachers need to know the ability to communicate effectively, recognizing others as well as 
learning from either the perceptions. Teachers ought to be able to enhance the understanding successfully. The principal objectives of the study were to study the impact of teacher's behaviour on the students' psychological and social development at the high school level.

Education is now generally accepted as the original key to a nation's social, educational, democratic, and socio-economic growth. The countries that took the important undertakings have made adaptive progress, and the last two decades have wrought miracles. This great accomplishment, it is, without doubt, premised on their advanced strategy of education and also any country's education structure and management allows assurance their nation's peace and stability. Educationally supportive conduct (e.g., offering platform for children to react, select, or receive constructive feedback) facilitates student performance and wellbeing (Curby et al., 2011).

(Hayon, 1989) states that teachers with qualified and personal skills are further efficient regarding their behaviour in classrooms, attitude and academic performance of the students. Each person has a diversity of perceptions which may be positive or negative and may differ with different attitudinal objects depending on their favourability and unfavourability. In reality, the impressions of children about school and classroom processes (such as teacher assistance and classroom environment) are frequently used in student studies (Reddy et al., 2003). Behaviour is a reaction that a person displays at various times to his or her setting.

It is fascinating to identify the appearances of the behaviour, attitudes, expertise, skills of teachers and their effect on the secondary students' academic accomplishment in Pakistan. Therefore, the right actions of secondary-level teachers, engagement with pupils, technical abilities, instructional skills, parental participation, student-owned skills, and secondary school climate all play a critical role in improving the capacity needed for better secondary-level academic achievement. (UNESCO, 1975) it suggested that role of the teacher in addition to the supervisor. School superintendents among all classifications and at all stages must be aware of the duties in the current educational context. Teachers must recognize that everyone's responsibilities and conducts aren't the same but revolve beneath the impacts of changes occurring in society as well as in the schooling institutions.

\section{Literature Review}

Abundant research promotes the notion that support for teachers has strong consequences for the psychological and social welfare of students (hereafter referred to as well-being). We conceive well-being as having positive and negative consequences in line with previous studies (Huebner \& Dew, 1996). The positive affect is to what degree a person usually experiences positive emotions (e.g., is excited, involved, and notify). Bad affect involves recurrent negative feelings (e.g., depression, frustration, nervousness). Well-being is not only of individual significance to students; negative influence is correlated with school issues including decreased completion of homework, reduced focus in class, less social interactions, weaker attendance and lower high school graduation rates (Jonsson et al., 2010). On the reverse, positive effect against school in students (e.g., school enjoying, feeling of connection) appears to be correlated with elevated classroom participation (Furrer \& Skinner, 2003).

Findings outlines that counseling for teachers plays a major role in the overall health of students. For example, students who feel encouraged by their teachers will also be more likely to feel comfortable and secure in classroom than their friends who have started experiencing discouraged. Also, students which consider their teachers as encouraging appear to show stronger psychological improvement), further optimistic impact and satisfaction with life, and reduced self-consciousness while at school (Roeser et al., 1996). Students who do not feel encouraged by teachers in school, on the other hand, have less dignity and established sense of belonging (Ryan et al., 1994). The findings of this research generally lead to the significance of exploring what particular teaching behaviours in students are correlated with prosperity. Strengthening the relations among students and teachers has important, positive and lasting implications for both students' social and academic development. Just strengthening the relationships between teachers and pupils would not yield achievement increases. However, certain individuals who have close, positive and cooperative relationships with their teachers can achieve outstanding results in their relationships than all the more divisive students.

(Gupta, 1996) defines teachers' duties as being fundamental to schooling. Teachers must pass on to the new generation, culture, and traditions of social structure, the experience gained over the years, the skills, practices and attitudes. They will also seek to cultivate the capacity to adapt to a continually evolving environment among their pupils. Good teacher has the potential to motivate students to learn. Even a western instructor approaches this description in our era. The instructor had progressed beyond just teaching, lecturing, doing evaluations and awarding grades; the instructor also plays the tasks of arranging, guiding, counselling, observing and assessing. The instructor also plays a key role in shaping society, in establishing a solid base for the maintenance of humanity and in making sure that such acts continue (Temel, 1988: 21).

Attitudes are indeed a structure which can involve emotions and feelings, whether positive or negative with regards to human substances and concerns. (Krech and Crutchfield, 1948) believe that people can have 
perceptions towards themselves and towards any indiscriminate component of their environment, for different degrees of favourability. There is a wide variety of attitudes towards somewhat vague values such as bravery, liberty and integrity.

To be encouraged to communicate with a teacher and exhibit positive actions including posing questions, knowing their feelings, expressing appreciation and enthusiasm improv inspiration and performance of the students. Even as continuing to provide students with material, knowledge and action on a given topic at a certain level of development, teacher becomes role models for students through their own actions and perception. Perceived benefits guarantee success and negative attitudes result in failure so as the result success will contribute to improved behaviours of the self-importance, while failure leads to negative attitudes of the self-image. For example, if the instructor participates in insulting remarks against a student due to his / her weakness, this will undoubtedly have the negative consequences.

Subsequent research focuses on the impact of positive teacher behaviour upon the encouragement level of pupils. The researcher has focused on teacher behaviours such as providing feedback for student works, complimenting, desiring to connect to students and being involved. Research results indicate that non-verbal acts of instructors including smile, maintaining a positive attitude, different movements and body language comes first in enhancing the learning environment for students while the subject of a classroom themselves takes second place. The success of the pupil isn't necessarily the product of their work; success is influenced by several factors but the first is the teacher's behavior. A teacher with positive attitude influences the encouragement of the student, the attitude concerning class and classwork, the self-confidence of the child and, as a result, the growth of character.

There's more to teaching than stating and describing. One of the most important aspects of daily teaching is the teacher's encouragement of the student and then for the teacher to place their constructive intentions to inspire the learner to understand. If the teacher's positive behaviour helps him / her to develop a healthy relationship with the students, it also enables the teacher to look into the children's motivation actions as opposed to the negative, thus carrying over a supporting position.

In this field of education in particular, socio-emotional skills are essential to develop students' character as they can enable them to control their anxiety, create and reach their objectives, navigate difficult circumstances, avoid being involved in dangerous behaviors, and maintain meaningful relationships with other students. These attributes, though, are also important for teachers (and the classroom staff and management) in order to improve effectiveness in teaching and controlling their curriculum, their contact with pupils, and their ability to influence the school environment - which in turn also influences pupil socio-emotional growth.
There are many ways of directly supporting the socio-emotional capabilities of students in the classroom, including, and not restricted to, utilizing socio-emotional vocabulary, comfort and encouragement, encouraging collaborative learning, helping children make informed choices, promoting dialogue in the classroom, bringing meaningful teaching into practice, introducing student-centered discipline and despite the approach, the aim is to enhance the performance of teacher-student interactions, the leadership of classrooms, the knowledge and skills of students and the willingness of educators to react with (interpersonal) students' needs.

(Wallace, 1994) shows that the actions of teachers supported by a sense of optimism, kindness, gratitude and pleasure becomes successful in changing and enhancing the behaviour of students who has similar reputations previously. But at the other hand, the negative practices among many teachers such as: reporting the disrespectful and uncoordinated students to the head of the school, bringing them out of class and having them sit in the corridor, recklessness and blatantly ignoring the severe problems of the students had an adverse impact on the behaviours of the student. Lack of leadership in school or classroom creates many problems for children and youth, which may be a source of disappointment for them. Even this deficiency can be seen in the job and anticipatory anxiety level of the instructor. (Crowley, 1993) found that when particular aspects of student-teacher relationships and engagement are valued, when teachers practice dynamic actions and avoid static and restrictive approaches, students embrace them as friends and partners. (Ferguson and Howton, 1992) discovered that one of the important elements of reciprocal recognition by teachers is to enhance students' involvement in performing educational tasks and experiments.

After home, the first fundamental establishment of socialization for the infant is school. Besides the relatives, it is the instructor of the student who is essentially around the front seat in terms of his / her character growth as well as academic and social success. The concept of modern education in every day places the task and obligation of becoming successful not only on the teacher's hands in the academic development of children as well as in character development. It is only sufficient to accomplish this obligation by allowing the educator to establish himself great personality values and to provide productivity in his relationships with students so that they can grow every personalities honestly (Inelmen, 2011).

The skills and features needed to become a great teacher are often the same consideration that describe a quality education. A good teacher includes eight basic characteristics: awareness of materials; decision making; practical thoughts and concern - solving ability; self-understanding and self-correction; observing; identifying students' learning needs and educating students; introducing new discoveries in teaching; instruction and interpersonal skills. 
Teachers can more directly shape people's views than they ever could, including its general public. They could even achieve received position by conducting in a manner that requires the admiration of regular citizens that recognizes the intervention of the other. While this status and pay of teachers are unlikely to rise enough to be significantly satisfied, they must be dissatisfied. Everyone who seeks to challenge what that offers particular occasions for development alongside socio-relevance might do excellent to pursue a change in teaching (Smith, 1994).

Anybody who deliberates teaching a vocation presumes the authority to perform him according to the profession 's principles. The teacher remains under intense surveillance from his students and society at bulky. Consequently, each teacher must see that his beliefs and practice are not incompatible. Her values must be the national principles of teaching that have being previously set out and will try to impart between students. Furthermore, the profession needs teachers to be relaxed, cautious and conversational by attitude and polite.

\section{Research Methodology}

This section comprises the tackles and methods of assortment and examination of data, being applied predominantly for testing of suggestion. The purpose of exploration was to discover the impact of teachers' behaviour on students' psychological and social development in Pakistan. The specific area, type and number of respondents was assumed to accomplish purposes of the deliberate study strategy. It would be a pointless effort deprived of taking up these deliberations. Therefore, the definition of these variables was necessary to make the study more scientific and decisive.

\subsection{Selected Area for Research}

Key intentions about this study were to find out the impact of teachers' behaviour on students' psychological and social development of Pakistan. Owing to some boundaries of time and monetary restrictions, the study was confined only to Tehsil Faisalabad. Faisalabad being the third-populous city in Pakistan and the second largest in eastern Punjab. The current study was carried out at the Faisalabad in Tehsil. The respondent of the survey incorporates students in the secondary school level. The sample size of 130 respondents were selected from ten high schools. 13 students will be selected randomly, thus making a sample size of 130 respondent.

\subsection{Pre-testing and Development of Questionnaire}

The questionnaire was established to assemble information from the respondent of secondary public students in Tehsil Faisalabad. That included open-ended questions in the questionnaire. Nine respondents were developed and tested for the survey. After pre-testing, the questionnaire engulfed necessary changes in light of the teacher's responses.

\subsection{Pre-testing}

The pre-testing was a questionnaire tryout to see how it works and whatever changes were compulsory before the actual collection of data. The developed and tested furnish means of catching and solving unpredicted questions in questionnaire administration. Ten questionnaires were distributed before collecting the real data to pre-test the validity of the questionnaire. Some mistakes were identified during assessing and removed to overcome the restrictions, data validity was improved.

\subsection{Validity of Questionnaires}

Validation is among the most significant research method facets. The group of educational experts asked to refine the products for the sake of its validity. To test the questionnaire, a three-point rating scale applied was the most relevant, and less important. The questionnaire contained 23 items. Mean value was determined from each subject, but mean values of 7 items became less than three, thus eliminating all those items from the data instrument.

\subsection{Reliability of Questionnaires}

The Cronbach's Coefficient Alpha was implemented for ensuring data's reliability found in the study. Pilot testing carried out on 130 secondary level students, which exempted from the final sample. The reliability coefficient was found at 0.87 .

\subsection{Result and Discussion}

Data were collected, and the statistics were investigated using the 'Statistical Package for Social Science' (SPSS). The data described using the frequency, percentage, and central tendency measurements (mean, standard deviation).

Table 1. Psychological Factors

\begin{tabular}{|c|c|c|c|c|}
\hline Factors & $\begin{array}{c}\text { Weighted } \\
\text { Score }\end{array}$ & $\begin{array}{c}\text { Rank } \\
\text { Order }\end{array}$ & Mean & $\begin{array}{c}\text { Std. } \\
\text { Deviation }\end{array}$ \\
\hline $\begin{array}{c}\text { Corporal } \\
\text { Punishment }\end{array}$ & 481 & 4 & 3.7 & 0.8 \\
\hline $\begin{array}{c}\text { Mental } \\
\text { Disturbance }\end{array}$ & 533 & 2 & 4.1 & 0.3 \\
\hline Social Media & 546 & 1 & 4.2 & 0.7 \\
\hline $\begin{array}{c}\text { Lack of } \\
\text { Confidence }\end{array}$ & 533 & 2 & 4.1 & 0.3 \\
\hline $\begin{array}{c}\text { Lack of } \\
\text { Motivation }\end{array}$ & 546 & 1 & 4.2 & 0.7 \\
\hline $\begin{array}{c}\text { Poor } \\
\text { Performance }\end{array}$ & 507 & 3 & 3.9 & 0.9 \\
\hline Phobias & 390 & 6 & 3.0 & 0.9 \\
\hline Less or no Help & 403 & 5 & 3.1 & 0.9 \\
\hline
\end{tabular}


While pointing out the psychological factors for research, the factors have been carefully taken by looking the influence of it, directly or indirectly and with supported by arguments and references. The youth of today is dependent on social media and this new world has placed pressure on adolescents. Formerly, contact and unrestricted exchange of opinions among people was restricted because of distances, and nowadays, even with citizenship or culture differences, the information flow and awareness continues through modern globalization of social networks. Social networking serves as a means of communication between adults and children entities where they are using various networks at their disposal to build, upload, communicate and discuss throughout themselves.

Psychosocial behaviour can be known as a response or reaction to how an person conducts and develops his / her interaction in the class setting, or wherever the person finds him / herself through the use of cell phones, tablets, laptops as well as other online services. The bad aspect of social networking sites has also been given fair consideration, such as cyberbullying, parent-child relationships, social anxiety and the impact of social media usage on sleep disruption and school success. The data observed in Table 1 pointed out about the psychological factors, top-ranking was given to such respondents' social media; and lack of motivation with a weighted score of 546, mean as 4.2 and the standard deviation valued as 0.7 .

Psychological problems can affect many aspects of student's life, decreasing overall standard of living, academic performance, physical health, and school experience fulfillment, and adversely affecting interactions with friends and family members. The 2nd ranking was that the respondents' lack of confidence and mental disturbance with a weighted score of 533, mean as 4.1 and standard deviation value as 0.3 . Such problems can also impact students' future careers, earnings prospects and overall health. (Eisenberg, et al., 2007). The 3rd ranking was about the poor performance in studies with a weighted score of 507, mean as 3.9 and standard deviation as 0.9. Less optimism, verbal nervousness and low self-esteem in classroom are now almost frequent issues. Pupils with low self-confidence are also unable to manage themselves in class for presentation skills, such as controlling his / her actions on what his / her peers think, losing self-confidence, believing his / her buddies are disappointed, fearing accidents, etc.

Corporal punishment is a disciplinary act in which pain is inflicted. It involves punching, kicking, slapping or imposing an awkward position on a child. Teachers in schools and home families use punishment as the most effective ways to monitor the actions and supervision of the children. From the psychological perspective, punishment is described as something that diminishes the incidence of a behaviour, physical discomfort, removal of affection, loss of measurable or function, admonish or anything else may be satisfying, but the person doesn't want it.
Corporal punishment has been correlated with a number of psychological and behavioural problems in adults and children, including anxiety, depression, isolation, low self-esteem, impulsivity, delinquent behavior and drug abuse (McCord, 1991). However, one of the factor have received 4th ranking was the corporal punishment with a weighted score of 481 , mean as 3.7 and standard deviation valued as 0.8 . Parents and teachers are more enlightened than before, however there is still room for improvement.

The 5th ranking was the need for a subject specialist with a weighted score of 403, mean of 3.1 and standard deviation recorded at 0.9. Phobias can interrupt the everyday activities and can cause extreme depression and anxiety. These signs are more likely to trigger complex phobias, such as agoraphobia and social phobia. People with phobias often intentionally avoid getting in touch with the thing causing them terror and anxiety. The reason why it got the least ranking as phobias are mostly rare, with a weighted score of 390, mean as 3.0 and standard deviation valued as 0.9 .

Table 2. Socio-Economic Factors

\begin{tabular}{|c|c|c|c|c|}
\hline Factors & $\begin{array}{c}\text { Weighted } \\
\text { Score }\end{array}$ & $\begin{array}{c}\text { Rank } \\
\text { Order }\end{array}$ & Mean & $\begin{array}{c}\text { Std. } \\
\text { Deviation }\end{array}$ \\
\hline $\begin{array}{c}\text { Environment at } \\
\text { home/school }\end{array}$ & 598 & 1 & 4.6 & 0.5 \\
\hline $\begin{array}{c}\text { Relationship with } \\
\text { teachers }\end{array}$ & 507 & 6 & 3.9 & 0.8 \\
\hline Book learning & 520 & 5 & 4.0 & 0.7 \\
\hline $\begin{array}{c}\text { Teacher } \\
\text { competency }\end{array}$ & 507 & 6 & 3.9 & 0.8 \\
\hline $\begin{array}{c}\text { Communication } \\
\text { skill }\end{array}$ & 546 & 3 & 4.2 & 0.4 \\
\hline $\begin{array}{c}\text { Over-crowding } \\
\text { class }\end{array}$ & 507 & 6 & 3.9 & 1.0 \\
\hline $\begin{array}{c}\text { Lack of } \\
\text { appreciation }\end{array}$ & 533 & 4 & 4.1 & 0.5 \\
\hline $\begin{array}{c}\text { Teacher student } \\
\text { interaction }\end{array}$ & 559 & 2 & 4.3 & 0.9 \\
\hline
\end{tabular}

The socio-economic factors for study were carefully taken by looking directly or indirectly at its effect and with reasons and references in support of it. Home and School, both are the important places for any student to get their psychological and socialization grooming which have direct connection with their development. The data represented in Table 2 pointed out about the socio-economic related factors which affects students' psychological and social development. The factor which got top ranking was given to environment at home/school with a weighted score of 598, mean of 4.6 and standard deviation valued as 0.5. Any disturbance in home environment, such as, parents arguing, financial problems, single parent, would affect the students psychological and social achievement. Same for school, if teachers are not supporting, teacher-student interaction declines. Less teacher-student interactions will restrict students' asking about the lesson or any question, lowering their morale and attentiveness. The 2nd ranking was that the teacher-student 
interaction with a weighted score of 559, mean as 4.3 and standard deviation evaluated as 0.9 .

The 3rd ranking was communication skill with a weighted score of 546, mean as 4.2 and standard deviation esteemed as 0.4. Communication skills enable students to listen and understand teachers' views in the classroom. After responding to and knowing what teachers say about students, they can confidently ask more questions, and this will help them gain further information and boost their activeness. Appreciation was described as recognizing the importance and significance of doing something - an activity, an individual, a behaviour, an artifact - and experiencing a meaningful emotional bond with it (Adler \& Fagley, 2005). The 4 th ranking was the lack of appreciation with a weighted score of 533, mean as 4.1 and standard deviation valued as 0.5 . Less or no appreciation will reduce the student's excitement to do or interact further as well as harm their self-confidence.

The 5th ranking was book learning with a weighted score of 520, mean as 4.0 and standard deviation recorded as 0.7 . Some students find it hard to learn from the textbook, in its place a practical or presentation could provide an overwhelming effect on students' understanding, enhance their confidence and morale. Not suitable classroom environment which can include overcrowded classes, lighting issues etc., which harms student's psychological development. The 6th ranking was about the relationship with teachers, teacher competency and over-crowding classes with a weighted score of 507, mean as 3.9 and standard deviation valued as 1.0 .

\section{Conclusions}

The study was conducted to determine how teachers' behaviour affects students' psychological and social development. Another objective was to find out students' psychological and socio-economic factors that create a hurdle in their achievements. While finding out the psychological factors, the close factor as social media to what end the respondents out of 130, majority of the respondents (40\%) agreed and strongly agreed that social media have weighted score of 546, mean as 4.2 and standard deviation valued as 0.7 , ranking 1 st.

Social media nowadays enable students to get in touch with the affairs of the world, news and knowledge about their fields. However, social media can harm students' academic achievements as students may get addictive in social media by indulging in texting and games which drain their time and energy and reduce to concentration in studies. Social media can also disturb the personality of students as they avoid physical exercises and head-on conversations.

While, finding out the socio-economic factors about the impact of teachers' behaviour on students' psychological and social development, Table 2 shows that such as environment at home and at school, most of the respondents (60\%) strongly agrees with a weighted score of 598, mean as 4.6 and standard deviation valued as 0.5 , ranking 1st. Family environment plays significant part in improving the academic accomplishments of the students. As friendly and supporting family members and relatives will reduce the pressure and burden on the children and raise their motivation to indulge in studies and competitions and gain better outcomes in high school.

\section{Recommendations}

To improve the psychological and social development of students, parents must try to recognize their children home or other crises because it unsettles their thinking as it makes them unmotivated from studies. Students learn at home and school, so the well-being of both these environments are compulsory. Corporal punishments must be abandoned, as these reduced the students' self-confidence and the ability to socialize. Not only that, corporal punishments are discouraged due to harm physically. Instead, teachers should introduce other means not as punishment, but as a penalty like, increasing homework, delay the off time, etc.

Teachers should know to treat the children well and help them by listening and solving their problems, making them feel comfortable and reduce the weight from their studies. Better teacher-student interactions provide students an opportunity to ask their questions and fulfill their curiosity. Also, for teachers, better interactions will allow them to understand their student's psychology and provide them the support they need.

Schools should stay attentive during their classes and their facilities as the classroom should not be hassled, better lighting and proper hygiene must be offered to students. Schools should also arrange co-curricular activities and competitive events, which will boost participation in the class and help students to become more active and confident. Also, it will allow students to polish their talents, cultures and attitudes.

\section{REFERENCES}

[1] Adler, M. G., Fagley, N. S, Appreciation: Individual differences in finding value and meaning as a unique predictor of subjective well-being, Journal of Personality, vol 73, no. 1, pp 79-114, 2005.

[2] Crowley, E. Paula, A qualitative analysis of mainstreamed behaviorally disordered aggressive adolescents' perceptions of helpful and unhelpful teacher attitudes and behaviors, Exceptionality, vol. 4 no. 3, pp. 131-135, 1993.

[3] Curby, T. W., Rudasill, K. M., Edwards, T., \& Perez-Edgar, $\mathrm{K}$, The role of classroom quality in ameliorating the academic and social risks associated with difficult temperament, School Psychology Quarterly, vol. 26, no. 2, pp 175, 2011. 
[4] Eisenberg, D., Gollust, S. E., Golberstein, E., \& Hefner, J. L, Prevalence and correlates of depression, anxiety, and suicidality among university students, American Journal of Orthopsychiatry, vol. 77, no. 4, pp. 534-542, 2007.

[5] Ferguson, Elizabeth., \& Houghton, Stephen, The effects of contingent teacher praise, as specified by Canter's Assertive Discipline Programme, on children's on - task behavior, Educational studies, vol.18, no. 1, pp, 83-93, 1992.

[6] Furrer, C., \& Skinner, E. Sense of relatedness as a factor in children's academic engagement and performance, Journal of Educational Psychology, vol. 95, no. 1, pp. 148-162, 2003.

[7] Gupta, S. M, “Teacher Education in the Changing Scenario”, Parkash Brothers, Ludhiana, India, pp. 48, 1996.

[8] Hayon, L. K, “The International Encyclopedia of Teacher Education”, Paragon Press, London, UK. pp. 83, 1989.

[9] Huebner, E. S., \& Dew, T, The interrelationships of positive affect, negative affect and life satisfaction in an adolescent sample, Social Indicators Research, vol. 38, no. 2, pp 129-137, 1996.

[10] Inelmen E, Integrating all learning activities around a city study curriculum, Cypriot Journal of Educational Sciences, vol. 6, no. 1, pp. 37-45, 2011.

[11] Jonsson, U., Bohman, H., Hjern, A., von Knorring, L., Olsson, G., \& von Knorring, A-L, Subsequent higher education after adolescent depression: A 15-year follow-up register study, European Psychiatry, vol. 25 no. 7, pp. 396-401, 2010.
[12] Krech, D. and R.S. Crutchfield, "Theory and Problem of Social Psychology”, McGraw Hill, New York, USA, pp. 152, 1948.

[13] McCord, J, Questioning the Value of Punishment, Social Problems, vol. 38 no. 2, pp. 190-200, 1991.

[14] Reddy, R., Rhodes, J., \& Mulhall, P, The influence of teacher support on student adjustment in the middle school years: A latent growth curve study, Development and Psychopathology, vol. 15, no. 1, pp 119-138, 2003.

[15] Roeser, R., Midgley, C., \& Urdan, T, Perceptions of the school psychological environment and early adolescents' psychological and behavioral functioning in school: The mediating role of goals and belonging. Journal of Educational Psychology, vol. 88, no. 3, pp. 408-422, 1996.

[16] Ryan, R., Stiller, J., \& Lynch, J, Representations of relationships to teachers, parents, and friends as predictors of academic motivation and self-esteem, Journal of Early Adolescence, vol. 14 no. 2, pp. 226-249, 1994.

[17] Smith, N. A, “Educational Psychology”, A Developmental Approach, 5th Ed., London, UK, pp. 251, 1994.

[18] Temel, A, Teacher from the perspective of a student, Quarterly Journal of Contemporary Education Education, vol. 13, no. 129, pp. 21-27, 1988.

[19] UNESCO, "International Conference on Education”, 35th session, Geneva, pp. 59, 1975.

[20] Wallace, Gary Ray, Discipline that motivates, Journal of Instructional Psychology, vol. 21 no. 4, pp 371-374, 1994. 